\title{
Knowledge, attitude, and practices of family planning methods among women of reproductive age attending OPD in tertiary care centre, Lucknow, Uttar Pradesh
}

\author{
Fareha Khatoon ${ }^{1}$, Garima Maurya ${ }^{2, *}$, Nagma $^{3}$, Parul Sinha ${ }^{4}$ \\ 1,2,4Assistant Professor, ${ }^{3}$ Junior Resident, Dept. of Obstetrics and Gynaecology, Era's Lucknow Medical College, Uttar Pradesh, \\ India
}

*Corresponding Author:

Email: maurya29121986@gmail.com

\begin{abstract}
Introduction: India, with 1.34 billion people is the second most populated country in the world, while china is on the top with over 1.41 billion people. Total fertility rate of India is 2.2 and the current total fertility rate of U.P is 3.72 which is still lagging behind other states like Kerela, Tamilnadu. Since the inception of program, several knowledge, attitude and practices studies have been conducted.

Materials and Methods: A cross sectional descriptive study was done in department of obstetrics and gynaecology, Era's Lucknow medical college, Lucknow, Uttar Pradesh. The study group include 523 married women of reproductive age group attending Gynaecology OPD. The results are presented in frequencies and percentages. Chi-square test is used for comparisons. The p-value $<0.05$ was considered significant. All the analysis was carried out on SPSS 16.0 version (Chicago, Inc., USA).

Results: Among the 523 women of reproductive age group maximum respondents belong to age group 21-30 years (78.77\%). Most of the contraceptive non-users belongs to age below 20 years $(64.7 \%)$ which is statically significant $(\mathrm{p}$ value $=0.008)$. among respondents majority were Hindus (64.2\%). Majority of respondents belongs to lower class (49\%). Among lower class $67 \%$ respondents were non-contraceptive users. Among the temporary methods, condom is the well - known method, $78.8 \%$ and second most is oral contraceptives $76.1 \%$ followed by intrauterine devices (75.5\%). Only $9.9 \%$ women knew about injectables. $77.8 \%$ women had positive attitude towards contraceptive usage and they would like to encourage others also for contraceptive usage.

$64.9 \%$ women not practicing any family planning methods because of lack of knowledge while $18.7 \%$ women not using any contraceptive methods because of fear of side effects.

Conclusion: In our study we observed that with increasing educational status and socioeconomic status contraceptive practices is increasing. We need more services to improve women's education and proper family planning counseling to allay the anxiety and fear about contraceptive usage. Also, women should be educated regarding available modern contraceptive methods.
\end{abstract}

Keywords: Family planning, Knowledge, Attitude, Practices.

\section{Introduction}

India, with 1.34 billion people is the second most populated country in the world, while china is on the top with over 1.41 billion people. With the population growth rate at $1.2 \%$, India is predicted to have more than 1.53 billion people by the end of 2030. Total fertility rate of India is 2.2 and the current total fertility rate of U.P is 3.72 which is still lagging behind other states like Kerela, Tamilnadu. ${ }^{2}$ One of the most proximate determinents of fertility is effective use of contraceptives. There is clear relationship between total fertility rate and contraceptive prevalence rate contraceptive prevalence is influenced by two factors: demand for fertility regulations and use of contraceptive to meet such demand. The demand will be influenced by socio-economic and cultural factors and perceived costs and benefits of having children and couples would demand contraception, if low fertility rates were considered beneficial, the programmed are supposed to meet this demand. ${ }^{3}$ The need of family planning in order to control population explosion lies to avoid unwanted pregnancies, control births, regulate the interval between pregnancies, control the time at which birth occur in relation to the age of the parent, and determine the number of children in the family. ${ }^{4}$ The
Government of India launched a family welfare program in 1950 to accelerate the economic and social development by reducing the population growth but this programme has met with only marginal success. This is because people of India being multireligious, multilinguistic and multiethinic have different level of awareness and acceptance of family planning. So, it is necessary to develop special program which can tackle the family planning of different groups. But before launching a special program, a thorough understanding of sociodemographic variables, knowledge, attitude and practices of family planning is necessary. Thus, with this background, our study was conducted with the objective to assess the knowledge, attitude and practices of different types of family planning method among women of reproductive age group and to find out any correlation between practices of family planning methods and their sociodemographic variables and to identify the reason precluding the practices of contraceptive methods.

\section{Materials and Methods}

A cross sectional descriptive study was done in department of obstetrics and gynaecology, Era's Lucknow medical college, Lucknow, Uttar Pradesh. 
The study group include 523 married women of reproductive age group attending Gynaecology OPD. The women are interviewed with predesigned pretested well - structured questionnaire. The dependent variables is awareness, attitude, practices and preference contraceptive methods. Independent variables were age, religion, education level, occupation socioeconomic status, age at marriage, number of pregnancies, number of living children, source of information. The results are presented in frequencies and percentages. Chi-square test is used for comparisons. The p-value $<0.05$ was considered significant. All the analysis was carried out on SPSS 16.0 version (Chicago, Inc., USA).

\section{Results}

Among the 523 women of reproductive age group maximum respondents belong to age group 21-30 years $(78.77 \%)$. Most of the contraceptive non-users belongs to age below 20 years $(64.7 \%)$ which is stastically significant ( $\mathrm{p}$ value $=0.008)$. among respondents majority were Hindus (64.2\%). Majority of the women belongs to secondary level education $(41 \%)$ and the contraceptive usage increases with increasing educational status use of contraception is $78.4 \%$ with primary level education, $71.7 \%$ with middle, $73.8 \%$ with secondary and $69.5 \%$ with graduation whereas only $46 \%$ contraceptive usage seen among illiterate group. Majority were housewives $(93.1 \%)$ in this study, percentage of non-users were also high (31.2\%) among housewives. Majority of respondents belongs to urban areas $(67.3 \%)$. Majority of respondents belongs to lower class (49\%). Among lower class $67 \%$ respondents were non-contraceptive users. With increasing class, contraceptive usage found increased i.e. $100 \%$ with upper class. contraceptive usage is highest with women who married before 18 years $(90 \%)$ and women whose married life was of duration more than 7 years as they completed their family $(73.3 \%)$. contraceptive use was high $(79.5 \%)$ among women with children more than 1 .

Table 1: Socio-demographic profile the subjects

\begin{tabular}{|c|c|c|c|c|c|c|}
\hline \multirow{2}{*}{$\begin{array}{c}\text { Socio-demographic } \\
\text { profile }\end{array}$} & \multirow{2}{*}{ No. of subjects } & \multicolumn{2}{|c|}{ User } & \multicolumn{2}{|c|}{ Non-user } & \multirow{2}{*}{ p-value } \\
\hline & & No. & $\%$ & No. & $\%$ & \\
\hline \multicolumn{7}{|l|}{ Age in years } \\
\hline $18-20$ & 17 & 6 & 35.3 & 11 & 64.7 & \multirow[t]{4}{*}{$0.008^{*}$} \\
\hline $21-25$ & 212 & 153 & 72.2 & 59 & 27.8 & \\
\hline $26-30$ & 200 & 146 & 73.0 & 54 & 27.0 & \\
\hline$>30$ & 94 & 62 & 66.0 & 32 & 34.0 & \\
\hline \multicolumn{7}{|l|}{ Religion } \\
\hline Hindu & 336 & 238 & 70.8 & 98 & 29.2 & \multirow[t]{2}{*}{0.65} \\
\hline Muslim & 187 & 129 & 69.0 & 58 & 31.0 & \\
\hline \multicolumn{7}{|l|}{ Educational level } \\
\hline Illiterate & 50 & 23 & 46.0 & 27 & 54.0 & \multirow[t]{5}{*}{$0.002 *$} \\
\hline Primary & 37 & 29 & 78.4 & 8 & 21.6 & \\
\hline Middle & 127 & 91 & 71.7 & 36 & 28.3 & \\
\hline Secondary & 214 & 158 & 73.8 & 56 & 26.2 & \\
\hline Graduate+ & 95 & 66 & 69.5 & 29 & 30.5 & \\
\hline \multicolumn{7}{|l|}{ Occupation } \\
\hline Housewife & 487 & 335 & 68.8 & 152 & 31.2 & \multirow[t]{3}{*}{$0.03 *$} \\
\hline Unskilled worker & 13 & 11 & 84.6 & 2 & 15.4 & \\
\hline Professional & 23 & 21 & 91.3 & 2 & 8.7 & \\
\hline \multicolumn{7}{|l|}{ Habitant } \\
\hline Rural & 171 & 121 & 70.8 & 50 & 29.2 & \multirow[t]{2}{*}{0.83} \\
\hline Urban & 352 & 246 & 69.9 & 106 & 30.1 & \\
\hline \multicolumn{7}{|l|}{ Socioeconomic status } \\
\hline Upper & 02 & 02 & 100 & 00 & 00 & \multirow{5}{*}{$0.001 *$} \\
\hline Middle & 182 & 117 & 64.3 & 65 & 35.7 & \\
\hline Lower middle & 21 & 13 & 61.9 & 8 & 38.1 & \\
\hline Upper lower & 63 & 28 & 44.4 & 35 & 55.5 & \\
\hline Lower & 255 & 84 & 32.9 & 171 & 67.0 & \\
\hline \multicolumn{7}{|l|}{$\begin{array}{l}\text { Age at marriage } \\
\text { (years) }\end{array}$} \\
\hline$<18$ & 50 & 45 & 90.0 & 5 & 10.0 & \multirow[t]{3}{*}{$0.005^{*}$} \\
\hline $18-25$ & 460 & 314 & 68.3 & 146 & 31.7 & \\
\hline$>25$ & 13 & 8 & 61.5 & 5 & 38.5 & \\
\hline \multicolumn{7}{|l|}{ Duration of marriage } \\
\hline$\leq 1$ & 33 & 17 & 51.5 & 16 & 48.5 & \multirow[t]{2}{*}{0.05} \\
\hline $2-4$ & 106 & 70 & 66.0 & 36 & 34.0 & \\
\hline
\end{tabular}




\begin{tabular}{|l|c|c|c|c|c|c|}
\hline $5-7$ & 148 & 107 & 72.3 & 41 & 27.7 & \\
\hline$>7$ & 236 & 173 & 73.3 & 63 & 26.7 & \\
\hline No. of pregnancy & & & & & & \multirow{2}{*}{$0.0001^{*}$} \\
\hline 0 & 29 & 8 & 27.6 & 21 & 72.4 & \\
\hline 1 & 92 & 61 & 66.3 & 31 & 33.7 & \\
\hline 2 & 162 & 110 & 67.9 & 52 & 32.1 & \\
\hline$\geq 3$ & 240 & 188 & 78.3 & 52 & 21.7 & \\
\hline No. of living children & & & & & & \multirow{2}{*}{$0.0001^{*}$} \\
\hline 0 & 73 & 30 & 41.1 & 43 & 58.9 & \\
\hline 1 & 156 & 124 & 79.5 & 32 & 20.5 & \\
\hline 2 & 173 & 123 & 71.1 & 50 & 28.9 & \\
\hline$\geq 3$ & 121 & 90 & 74.4 & 31 & 25.6 & \\
\hline
\end{tabular}

${ }^{1}$ Chi-square test

Among 523 respondents 490 women were heard about family planning and for $49.3 \%$ respondents media is the source of information followed by friends/ relatives which is $27.5 \%$. $14.5 \%$ women got knowledge about family planning methods from health professionals. Among the temporary methods, condom is the well - known method, $78.8 \%$ and second most is oral contraceptives $76.1 \%$ followed by intrauterine devices (75.5\%). Only 9.9\% women knew about injectables. Among permanent methods, $73.8 \%$ women had knowledge of female sterilization. According to the most of the women, family planning methods are meant for limitations of birth $(38.4 \%)$ and $23.7 \%$ meant for spacing of birth while for $3.4 \%$ women meant for both limitation and spacing of birth. Among respondents $62 \%$ women knew that family planning methods also prevents from STDs, while $5.4 \%$ knew it help in improvement of health and $8.6 \%$ knew that it protects from cancer. $17.8 \%$ women had no idea regarding noncontraceptive benefits of family planning.

Table 2: Knowledge and awareness regarding family planning methods

\begin{tabular}{|l|c|c|}
\hline \multicolumn{1}{|c|}{ Knowledge and awareness } & $\begin{array}{c}\text { No. } \\
\text { (n=523) }\end{array}$ & \% \\
\hline Heard about family planning & 490 & 93.7 \\
\hline Source of information & & \\
\hline Media & 258 & 49.3 \\
\hline Friends/Relatives & 144 & 27.5 \\
\hline Health professionals & 76 & 14.5 \\
\hline Others & 12 & 2.3 \\
\hline Contraceptive methods known & & \\
\hline Condom & 412 & 78.8 \\
\hline Oral contraceptive pills & 398 & 76.1 \\
\hline Intrauterine devices & 395 & 75.5 \\
\hline Injectables & 52 & 9.9 \\
\hline Natural methods & 308 & 58.9 \\
\hline Female sterilization & 386 & 73.8 \\
\hline Male sterilization & 294 & 56.2 \\
\hline No idea & 45 & 8.6 \\
\hline $\begin{array}{l}\text { Concept regarding family } \\
\text { planning }\end{array}$ & & \\
\hline Limitation of births & 201 & 38.4 \\
\hline Spacing of births & 124 & 23.7 \\
\hline Stopping birth & 22 & 4.2 \\
\hline Limitation of birth and spacing & 18 & 3.4 \\
\hline
\end{tabular}

\begin{tabular}{|l|c|c|}
\hline of birth both & & \\
\hline No idea & 125 & 23.9 \\
\hline $\begin{array}{l}\text { Knowledge of non- } \\
\text { contraceptive benefits of } \\
\text { family planning methods }\end{array}$ & & \\
\hline Prevention from STD & 324 & 62.0 \\
\hline Improvement of health & 28 & 5.4 \\
\hline Protection against cancer & 45 & 8.6 \\
\hline No idea & 93 & 17.8 \\
\hline
\end{tabular}

Among 523 respondents, $77.8 \%$ women had positive attitude towards contraceptive usage and they would like to encourage others also for contraceptive usage. Among 156 present non-contraceptive users 120 $(76.9 \%)$ women had positive attitude to adopt family planning methods while $36(23.1 \%)$ women still did not want. Among temporary methods, $65 \%$ women would like to use condom and $15 \%$ women choose OCPs followed by intrauterine devices chosen by $13.3 \%$ women. $4.2 \%$ women choose female sterilization and $2.5 \%$ male sterilization.

Table 3: Attitude towards use of family planning methods

\begin{tabular}{|l|c|c|}
\hline $\begin{array}{c}\text { Would practice family planning } \\
\text { methods or encourage others }\end{array}$ & & \\
\hline Yes & 407 & 77.8 \\
\hline No & 116 & 22.2 \\
\hline Knowledge and awareness & $\begin{array}{c}\text { No. } \\
(\mathbf{n = 1 5 6})\end{array}$ & $\mathbf{\%}$ \\
\hline $\begin{array}{l}\text { Will adopt family planning } \\
\text { methods (If not using currently) }\end{array}$ & & \\
\hline Yes & 120 & 76.9 \\
\hline No & 36 & 23.1 \\
\hline Type of method & & \\
\hline Condom & 78 & 65.0 \\
\hline Oral contraceptive pills & 18 & 15.0 \\
\hline Intrauterine contraceptive device & 16 & 13.3 \\
\hline Injectables & 0 & 0.0 \\
\hline Natural method & 0 & 0.0 \\
\hline Female & 5 & 4.2 \\
\hline Male & 3 & 2.5 \\
\hline
\end{tabular}

Among 523 respondents, 298(57\%) women had used contraceptive in past. $66.4 \%$ women use condom followed by $17.4 \%$ used OCPs followed by $16.1 \%$ used IUCDs.69.8\% women choose family planning method 
because they are easily available while $62.4 \%$ women found it comfortable and easy to use. in $50.3 \%$ of women, the choice of method use was decided by husband's choice.

Barrier to using contraceptive: $64.9 \%$ women not practicing any family planning methods because of lack of knowledge while $18.7 \%$ women not using any contraceptive methods because of fear of side effects. $10.7 \%$ were not using as they were planning for pregnancy. $3.6 \%$ thought it to be against religion and $2.2 \%$ had some myths regarding contraceptive usage.

Table 4: Use of family planning methods in the past

\begin{tabular}{|c|c|c|}
\hline Used in the past & $\begin{array}{c}\text { No. } \\
(n=523)\end{array}$ & $\%$ \\
\hline Yes & 298 & 57.0 \\
\hline No & 225 & 43.0 \\
\hline Contraceptive used in past & $\mathrm{n}=298$ & \\
\hline Condom & 198 & 66.4 \\
\hline OCPS & 52 & 17.4 \\
\hline IUCDS & 48 & 16.1 \\
\hline Injectables & 00 & 0.0 \\
\hline Female sterilization & 00 & 0.0 \\
\hline Male sterilization & 00 & 0.0 \\
\hline Others & 00 & 0.0 \\
\hline Reason for using them & $\mathrm{n}=298$ & \\
\hline Easily available & 208 & 69.8 \\
\hline Comfortable and easy to use & 186 & 62.4 \\
\hline Inexpensive & 12 & 4.0 \\
\hline Husband's choice & 150 & 50.3 \\
\hline Others & 08 & 2.7 \\
\hline $\begin{array}{l}\text { Reasons precluding women to } \\
\text { practice contraceptives }\end{array}$ & $\mathrm{n}=225$ & \\
\hline Lack of knowledge & 146 & 64.9 \\
\hline Unbearable side effects & 42 & 18.7 \\
\hline Against religion & 8 & 3.6 \\
\hline Myths & 5 & 2.2 \\
\hline Desire to have child & 24 & 10.7 \\
\hline
\end{tabular}

Statistical analysis

The results are presented in frequencies and percentages. Chi-square test was used for comparisons. The $\mathrm{p}$-value $<0.05$ was considered significant. All the analysis was carried out on SPSS 16.0 version (Chicago, Inc., USA).

\section{Discussion}

In our study contraceptive prevalence rate is $57 \%$ as compared to $40.7 \%$ which is the modern contraceptive prevalence rate of Uttar Pradesh according to national data 2015. A higher rate of $62.9 \%$ is also reported in a study conducted at Kanpur. In our study the higher contraceptive usage seen with increasing age and parity. similar results were seen in the study conducted at Kanpur, where $75.3 \%$ contraceptive usage was found among age group 21-34 years and $74.7 \%$ contraceptive users were of parity $>3$. Mohanan et al., ${ }^{5}$ also highlighted that acceptors of contraception were of higher age and parity. According to Park et al, the older the women, the more frequently they were exposed to family planning methods. ${ }^{6}$ In our study we found contraceptive usage increases with increase in literacy, $78.4 \%$ contraceptive usage was seen in primary educated women and only $46 \%$ contraceptive usage was seen in illiterate women. Similar results were found in study conducted at Kanpur, they found $69.6 \%$ contraceptive usage in secondary and higher educated women and $62.6 \%$ in primary educated women. In other study, Gautam et al found that raise in education status helps in improving acceptance of contraceptive practices. ${ }^{7}$ In our study no difference was found in contraceptive usage depending on place of habitat.

About $70-80 \%$ of women with 1or more than 1 living children were using contraception in comparison to $41.1 \%$ by those having no living issues. This result is stastically significant with $\mathrm{p}=0.001$. Verma et al had also shown that $77.5 \%$ of women with 3 or more living issues were used contraceptive methods as compared to $35 \%$ of those having no live issues. Lasse et al had also shown that women with 3 or more living children are more likely to use contraception than if they had 2 or less. ${ }^{8}$ In our study higher percentage of awareness of family planning methods were found, $93.7 \%$ of women knew about atleast 1 method. In other studies the percent of awareness varied from $93.1 \%$ in Kanpur, 94.2\% in Sikkim, 94\% in Pakistan.

Around $93.7 \%$ of the respondents were heard about one or more of the various family planning methods, which is also similar to the results of Gupta et al $(62 \%)^{9}$ and study conducted at Kanpur. ${ }^{1}$ in present study, media $(49.3 \%)$ was found to be most common source of information followed by friends and relatives $(27.5 \%)$ and health professionals(14.5\%). Similar results were found in Kanpur study, Jahan U et al found mass media as main source of information followed by friends and relatives followed by health professionals. Most of the other studies also have stated media to be most common source of awareness whereas in Srivastava et al study, they found $70 \%$ had gained knowledge of contraception from friends and relatives and $39 \%$ from $\mathrm{TV}$ and radio. ${ }^{10}$

Regarding the usage of family planning methods, an important dimension is the type of family planning method used.

Among the temporary methods, condoms (78.8\%) was most known method followed by oral contraceptives $(76.1 \%)$ and IUCDs $(75.5 \%)$ similar to the study conducted by Jahan $\mathrm{U}$ et al where $74.8 \%$ subjects know about OCPs, $68.8 \%$ about condoms followed by IUCDs $(56.6 \%)$ and injectables $(38.4 \%)$. While in Gupta et al study female sterilization (45.6\%) was the most chosen method followed by IUCDs (23\%) and condoms $(22 \%)$; the least preference was given to OCPs $(9.2 \%)$.

In our study $8.6 \%$ were not aware of any method of contraception similar results were found in study 
conducted by Verma et al where 8.795 women were not aware of any form of contraception.

In permanent methods, our results showed that most of the women $(73.8 \%)$ had heard about female sterilization as compared to $56.2 \%$ about male sterilization. Verma et al also found female sterilization (36.4\%) as most known method in comparison to male sterilization i.e $25.3 \%$. In Gupta et al study, they also reported female sterilization as most chosen method $(95.6 \%)$ and male sterilization (89.6\%). ${ }^{9}$ This disparity may be because of common belief that reproduction is mainly the function of women and male sterilization causes decrease in sex drive in man.

When participants were interviewed about concept regarding family planning methods. The response obtained were $41.5 \%$ for limitation of births, $25.3 \%$ for spacing of births, $44 \%$ for stopping birth and $25.5 \%$ had no idea.

This study revealed $81.02 \%$ respondents had knowledge on non contraceptive benefits of family planning methods.

In this study $77.8 \%$ women has shown positive attitude towards contraception usage while negative attitude which was supported by a similar study conducted in TEZU village, MANIPAL where majority $60 \%$ had positive attitude.

In our study $43 \%$ women had not used any type of family planning method as compared to $37.1 \%$ in Verma et al's study where as $44.6 \%$ had never used any contraceptive method in Khati Binita study conducted in Sikkim in 2005. ${ }^{11}$

In our study $57 \%$ women had used atleast one method of contraception condom was most preferred method $66.4 \%$ followed by OCP's $17.4 \%$ and IUCDs $16.1 \%$. $69.8 \%$ women choose at least one contraceptive method because they are easily available.

$64.9 \%$ women not using any type of contraceptive method because of lack of knowledge, $18.7 \%$ had fear of unbearable side effects, $10.7 \%$ women had desire to have a child. Similar result were found in Verma et al study, where $32.1 \%$ stopped using contraceptive methods due to various reasons lie due to lack of knowledge in $42.4 \%$, side effects in $25.5 \%, 60.55$ desire to have next child.

\section{Conclusion}

In our study we observed that with increasing educational status and socioeconomic status contraceptive practices is increasing. In our study we found that awareness towards the family planning methods are good but contraceptive practices are poor because of lack of knowledge and fear of side effects therefore, we need more services to improve women's education and proper family planning counseling to allay the anxiety and fear about contraceptive usage.

Also, women should be educated regarding available modern contraceptive methods.
Health worker and mass media plays a important role in society to educate the people about different methods of contraception. Moreover family planning clinics should be run daily and strengthen the family planning services which are available at each level of health system.

Thus, this study reveals that educational status and socioeconomic status directly plays an important role in acceptance of family planning.

\section{Conflict of Interest: None}

Approved by Institutional ethical committee

\section{References}

1. Jahan U, Verma, Gupta S, Gupta R, Mahour S, Kirti N et al. Awareness, attitude and practices of family planning methods in a tertiary care hospital. Uttar Pradesh, India, Int. J Report contracept obstet gynecol 2017;6;500-6.

2. National family health survey 4 (2015-16). Available at http://www.rchiips.org/nfhs.

3. Parihar M, Bhalerao-Gandhi. A, Contraception past, present and future: $1^{\text {st }}$ edition 2006 3-5.

4. Park K. Park's textbook of preventive and social medicine, 23rd edition. New Delhi, India: Banarsidas Bhanot Publishers, 2015. Page 504-8.

5. Mohanan P, Kamath A, Sajjan BS. Fertility pattern and family planning practices in rural ares in Dakshina Kannada. Indian J com med.2003.

6. Park HJ, Chung KK, Han DS. Defferential effects of communication media on family planning behavior. Korean J. Prev. med. 1975;8:37-52.

7. Gautam AC, Seth PK. Appraisal of the knowledge, attitude and practices of family control devices among rural Rajputs and scheduled caste of Hatwar area in Bilaspur district. Himachal Pradesh Anthropologist. 2001;4:289-92.

8. Lasse A, Meeormic JB demographic and socioeconomic determinents of contraceptive use in a low income community in Karachi. J. Paistan med.

Assoc.1996;46:228-31.

9. Gupta V, Mohapatra D, Kumar V. Family planning knowledge, attitude, and practices among the currently married women (aged 15-45 years) in an urban area of Rohtak district, Haryana. Int J Med Sci Public Health 2016;5:627-632.

10. Srivastava R, Srivastava DK, JINA r. contraceptive Knowledge, Attitude and Practice survey. J Obstet Gynecol India. 2005;55:546-50.

11. Renjhen P, Gupta SD, Barua A. A study of Knowledge, attitude and practices of family planning among the women of reproductive age group in Sikkim. J. Obstet Gynecol India. 2008;58:63-7. 